\title{
Reseña de Regueiro, Sabina Amantze, Apropiación de niños, familias y justicia. Argentina (1976-2012), Rosario, Prohistoria Ediciones, 2012, 287 págs.
}

\author{
MARIANELA SCOCCO (UNR-CONICET) \\ Universidad Nacional de Rosario \\ Consejo Nacional de Investigaciones Científicas y Técnicas \\ marianob4@hotmail.com
}

Apropiación de niños, familias y justicia presenta una visión de conjunto sobre un tema que si bien ha sido abordado en numerosas investigaciones, ese abordaje ha sido de forma tangencial o parcial: se trata de la cuestión de la apropiación, identificación, localización y restitución de los hijos de detenidos-desaparecidos durante la última dictadura militar (1976-1983). Esta visión de conjunto es lograda gracias a un valioso acervo documental que le otorga a la investigación un importante sustento empírico. Es, además, el resultado de años de trabajo y participación de la autora en la asociación Abuelas de Plaza de Mayo (APM, en adelante), lo que le imprime al texto la calidad propia de quien se encuentra familiarizado, a nivel humano y académico, con el tema.

El propósito de la investigación, tal como su autora lo define, es, por un lado, estudiar la apropiación de hijos de detenidos-desaparecidos en la última dictadura militar y, por otro, explicar las localizaciones e identificaciones de los mismos a través de las acciones que promovieron las APM, analizando "las tramas sociales y políticas, a partir de las cuales fue posible la construcción de parentescos e identidades de niños apropiados, hijos de detenidosdesaparecidos, posteriormente localizados" (pág. 253), estudiadas a partir de su imbricación con el derecho y su articulación con la dimensión burocrática-administrativa.

De aquí se despliegan las hipótesis principales, anunciando el argumento general del libro el cual sostiene que el parentesco y la identidad de los niños apropiados son el resultado de un entramado social y político a partir del cual se instrumentó su apropiación, mientras que la tesis específica de la investigación se centra en que en esa construcción social de parentesco e identidad jugaron un papel muy importante tanto las burocracias estatales como las estrategias de APM.

Al mismo tiempo, los objetivos se corresponden con el análisis de distintos ámbitos burocráticoadministrativos que implicaron el estudio de espacios, tiempos y lógicas institucionales particulares, comenzado por el desempeño del Poder Judicial pero también de las maternidades clandestinas, la administración pública, las estrategias discursivas, etcétera. Para cumplir con estos propósitos, Regueiro trabaja específicamente con los casos de jóvenes resueltos hasta el año 2010, lo que certifica una amplia gama de situaciones que atraviesan tres décadas de restituciones, sin dejar de tener en cuenta -como resalta la autora- que éstos son apenas una quinta parte del total de los niños apropiados, debido a los que aún faltan restituir.

En este sentido, la estructura del libro presenta una arquitectura organizada en apartados claramente delimitados que permiten identificar todos los aspectos mencionados y que el futuro lector pueda efectuar un recorrido coherente a lo largo de la obra. Conforme a esta organización, la obra estructura sus primeras páginas a partir de la introducción y un primer capítulo que se destacan por una fuerte impronta teórico-metodológica donde se despliegan los objetivos, las hipótesis, el corpus teórico y el acervo documental, así como las estrategias de abordaje. Contiene un exhaustivo análisis de las fuentes analizadas, en relación a su verosimilitud y autenticad, su procedencia y autoría y el contexto histórico en el que fueron producidas. Por último, también 
reflexiona sobre la organización y selección que permitió la conservación de los documentos en los archivos.

Seguidamente el texto se divide en dos partes bien diferenciadas que se fundamentan en los dos propósitos principales del libro que, a su vez, responden a dos momentos bien diferenciados del proceso: la apropiación por un lado y la localización por el otro.

Si bien la problemática abordada en cada capítulo se despliega del anterior e introduce la temática del siguiente, los capítulos están ordenados problemática y en ocasiones cronológicamente, de tal forma que pueden ser leídos independientemente uno del otro, según los intereses del lector, sin que por esto pierdan su íntima conexión con los demás y con el argumento general de la obra. En la primera parte se delinea la secuencia de los discursos dictatoriales sobre la familia; las tramas burocráticas-administrativas de las maternidades clandestinas; las inscripciones falsas en la administración pública y las adopciones fraguadas. Esta primera parte concuerda cronológicamente con los años de dictadura. La segunda parte indaga sobre la búsqueda de las Abuelas de sus nietos desaparecidos. El recorrido es la instrumentación del análisis genético como método de identificación; las "batallas judiciales" para lograr las restituciones y las reinscripciones de las filiaciones de los jóvenes localizados. De allí que la centralidad de esta segunda parte se relacione con los periodos democráticos. La dicotomía entre dictadura y democracia recorre constantemente las estrategias de análisis desplegadas, tanto en la caracterización de los momentos históricos como en el abordaje de las fuentes.

La segunda parte, según la propia autora, es una especie de contrapunto de la primera, donde cada capítulo responde a uno anterior. Así, mientras en el segundo capítulo se abordan las concepciones familiares de la dictadura, en el sexto se plantea el lugar de lo genético en la construcción y reconfiguración de parentescos e identidades. Los que le siguen desarrollan tales procesos de construcción de parentescos e identidades a partir de la actuación de instituciones y tribunales de menores y juzgados civiles que concretaron las adopciones en el capítulo tercero y a partir de las causas judiciales orientadas a la localización y restitución de los niños apropiados en el séptimo. Por último, los capítulos cuarto, quinto y en contrapartida el octavo, reflexionan en torno al papel de los documentos personales en los procesos de (re)significación de identidad y parentesco, a través de prácticas y procedimientos de (re)inscripción, en el momento de las apropiaciones los primeros y de las restituciones el último.

Dentro de su corpus teórico se destacan los estudios sobre el parentesco y la identidad, pero también los debates en torno a la democracia y el derecho, devenidos sobre todo de la antropología jurídica local. Vale la aclaración de que, en su mayor parte, estos trabajos no se ocupan de la dimensión burocrática de la apropiación como lo hace esta investigación. A la vez, posee un corpus documental excepcional: el Archivo de APM, y su participación en este espacio la convierte en una consultora privilegiada, ya que -como la misma autora lo explicita - contó con la autorización para acceder a información reservada. Este archivo reúne documentos muy diversos: desde documentos oficiales de distinta naturaleza (actas, certificados, partidas de nacimiento, etcétera) y expedientes de causas judiciales, hasta notas periodísticas, narraciones de libros institucionales, fotos, conversaciones informales y entrevistas. Los documentos administrativos hicieron posible la reconstrucción de las tramas de relaciones, sentidos, prácticas y procedimientos que posibilitaron la apropiación y la restitución de los niños y jóvenes, tanto por lo que ocultan como por lo que manifiestan. En este sentido, el propio acervo documental del Archivo de APM es producto de esas estrategias jurídico-políticas desplegadas por APM en la búsqueda y restitución de los nietos. La autora además consultó la normativa referida a la reinscripción de los nacimientos (leyes, decretos, disposiciones, resoluciones, etcétera), registros de juicios orales y realizó sus propias entrevistas, que se cristalizan especialmente en el último capítulo. 
Precisamente por el carácter reservado de las fuentes que utiliza, la autora elige la estrategia de no mencionar la identidad de los niños o jóvenes apropiados, excepto en el último capítulo donde trabaja con las entrevistas que ella misma realizó. Sin embargo, muchos de los casos analizados han sido ampliamente conocidos por el estado público que han tomado las restituciones. En este sentido, sería interesante repensar si el estado actual de las investigaciones realizadas en historia reciente no otorgaría ya la oportunidad de superar este tipo de "restricciones" en cuanto a la identidad de los sujetos y ponerle nombre y apellido a los actores analizados.

Por otro lado, si bien el libro logra alcanzar -como ya señalamos- una visión de conjunto sobre la apropiación de los niños durante la última dictadura militar, consecuencia de su análisis sobre todos los casos de jóvenes localizados, lo que le otorgaría una suerte de carácter "nacional" a la investigación (en el sentido de síntesis sobre lo acaecido en todo el territorio nacional), al mismo tiempo peca de generalizar lo acontecido a partir del estudio de casos. Tal es el caso de las maternidades clandestinas, las cuales son analizadas a partir de la experiencia de las que funcionaron en Campo de Mayo: El Campito; el Hospital Militar y la cárcel de Encausados, proponiendo comparaciones con otras maternidades como las que se desempeñaron en la ESMA o en el "circuito Camps", lo que no deja de estar inmerso en la lógica Buenos Aires-La Plata. Si bien la autora hace la debida aclaración, creemos necesario avanzar en el estudio de otros espacios regionales, sin perder de vista la magnitud y la centralidad que tuvo Campo de Mayo en la represión y en los nacimientos clandestinos, siendo quizá precisamente por tal magnitud que la incorporación de otros casos a lo largo del país ayudaría a complejizar el análisis. Un abordaje de estas características podría cuestionar, por ejemplo, la caracterización de estos hechos como un "plan sistemático de apropiación de niños", que es claro y está bastante probado, incluso judicialmente, para el caso de Campo de Mayo y otros, pero que no se expresa de igual manera en todo el país. Esto último contribuiría a reforzar una de las hipótesis del capítulo tercero donde la autora sostiene, en base al examen de algunas "excepciones" que rompen "la regla" -según las propias palabras de la autora-, que "no habría una organización burocrática totalmente centralizada de distribución de los niños" (pág. 97).

Por su parte, Reguiero demuestra con amplitud los logros alcanzados por APM a partir de su participación política y social, que dieron diversos resultados: la declaración de imprescriptibilidad de las apropiaciones; la anulación de las adopciones plenas; la inclusión del derecho a la identidad en la legislación nacional e internacional; el impulso de la conformación de otras asociaciones; el índice de abuelidad; el Banco Nacional de Datos Genéticos, etcétera.

Concluyendo, la investigadora observa que las tramas sociopolíticas a partir de las cuales fue posible la (re)construcción de parentescos e identidades trascienden en mucho a las Fuerzas Armadas y de Seguridad, en donde se sitúan las burocracias estatales pero también las estrategias jurídico-políticas de APM. Así, reflexiona sobre la particularidad del caso argentino en cuanto a las relaciones sociales que hicieron posible la apropiación de menores pero, al mismo tiempo, desarrolla las formas de intervención y las prácticas políticas de APM que lograron no sólo la denuncia sino además obtener un consenso social sobre la atrocidad de las apropiaciones y pudieron restituir a cientos de niños y jóvenes apropiados. Por tanto, como afirma la autora, es en esta práctica donde estuvo marcada la ruptura que permitió la visibilización y problematización de este acontecimiento de una manera particular y marcó un hito significativo en la sociedad argentina. El libro de Regueiro da cuenta sobradamente de este proceso, por lo cual se convierte en un material de lectura relevante para la comprensión de este episodio central de la historia reciente del país. 